\title{
Supply side dynamics of Boutique Fashion in Bangladesh
}

\author{
Md. Al Mamun ${ }^{1}$, Sheikh Morshed Jahan ${ }^{1}$ \\ ${ }^{1}$ Institute of Business Administration, University of Dhaka, Bangladesh
}

\begin{abstract}
As a fast growing industry the boutique fashion is the lifeblood of Bangladeshi economy. There are a lots of potential small boutique wear producers for inclusive growth in our economy. However, few studies examined their development, challenges and future prospects. Therefore, the aim of this paper is to investigate the sustainability and growth potential of small boutique wear producers in Bangladesh. A survey and individual interviews were conducted with professionals and owners of the boutique fashions. A triple triangle factors analysis was used to indentify challenges at the firm internal, industry and macro level for ensuring sustainability and growth potential. Based on the findings, an action plan is proposed to take effective decisions in order to enhance the supply side dynamics in the long run. The study has implications for small boutique fashion wear producers and policymakers.
\end{abstract}

Keywords: Boutique, Fashion, Growth potential, Sustainability, Triple triangle framework

\section{Introduction}

The boutique fashion industry in Bangladesh has rapidly grown and become an important part of the economy. There are a lots of boutique shops available in our country which fulfilling the local demand of clothing vastly by their wide range of product varieties. Boutique house production passes on to the number of different product levels integrated in one product line. Productions have both operations and marketing implications. Producer supplies products to meet the demand and requirements of retailers along the customers. As a result, the boutique fashion industry has tremendous product variety, short product life cycles, unpredictable market demand, and inflexible supply processes (Sen, 2008). This paper is directed to boutique fashion in Bangladesh. It is an industry with approximately 5,000 boutique houses all over the country. The industry is the primary liaison among the producer, retailer and consumer. Producer works for retailers order. Retailers are then sales the fashion product to consumers.

In order to provide excellent boutique fashion, boutique producers in Bangladesh need diagnostic procedures that are creative, efficient and accurate. In addition, the producer should not be overly painful by the retailer. Unfortunately, producer carries just retailers order even the retailer provides fabrics and design. They have no choice. If producer continuous to do the procedures, they will unable to develop their creativity and over all entrepreneur approach for inclusive growth in the boutique fashion industry. Lack of entrepreneurial approach among small boutique fashion wear producers is prohibitive of inclusive growth for producer in the boutique fashion industry.

\subsection{Objectives of the study}

The primary objective for the study is to investigate sustainability and growth potential of small boutique fashion wear producers in Bangladesh.

For clearing the primary objective, the Specific objectives are given below:

1. To examine the business model of small boutique fashion wear producer.

2. To find relation between small boutique fashion wear producer and retailers/retail brands value chain governance perspective.

3. To examine the challenges faced by small boutique wear producer along with TTF dimensions.

4. To develop an action plan for inclusive growth in boutique fashion wear industry.

\subsection{Scopes of the study}

This study is specially focused on the prospects and hurdles faced by boutique fashion in supply side. Production, branding and retail of boutique fashion have been brought under the jurisdiction of the study. However, forward linkage link like marketing and backward link like fabrics, color and accessories have been left out of its domain. The area of this study will be limited to boutique male and female ethnic wear i.e. Salwar, Kurta, Kamiz, Panjabi, Orna and wearable accessories. The geographic scope will be limited to Small, Medium and Large Producers \& Retailers of Boutique Fashion Industry in Dhaka and within 20km radius of Dhaka.

\subsection{Methodology}

In order to achieve the objectives of this study, the research was involved qualitative and quantitative methods. The use of a mixed methodology approach, both qualitative and quantitative methods, was benefitted

DOI: $10.9790 / 487 X-1901063441 \quad$ www.iosrjournals.org $\quad 34 \mid$ Page


the research by giving a wider view and more evidence to analyze the issues. For the purposes of the study, the population is individual factory of boutique fashion in Bangladesh. A convenience sampling technique will be used to select the interviewers. Qualitative data were gathered from the qualitative survey by questioning 40 boutique owners in Dhaka city. A questionnaire with a seven point Likert scale was be used in the interview of the respondents. The study is based on the primary and secondary data. The primary data were collected from the in-depth interview of 30 small and medium boutique fashion enterprises in Dhaka city. The secondary data were collected from Business and Economic journals, Books and Government publications. As already noted, this study is exploratory in nature. This section includes organizational characteristics, external characteristics and influencers for boutique fashion.In order to analyze the sustainability and growth potential of the boutique industry in Bangladesh, triple triangle frameworks (TTF) techniques were used to synthesize the findings and to devise a strategic plan of action. The below figure 1 illustrates the TTF.

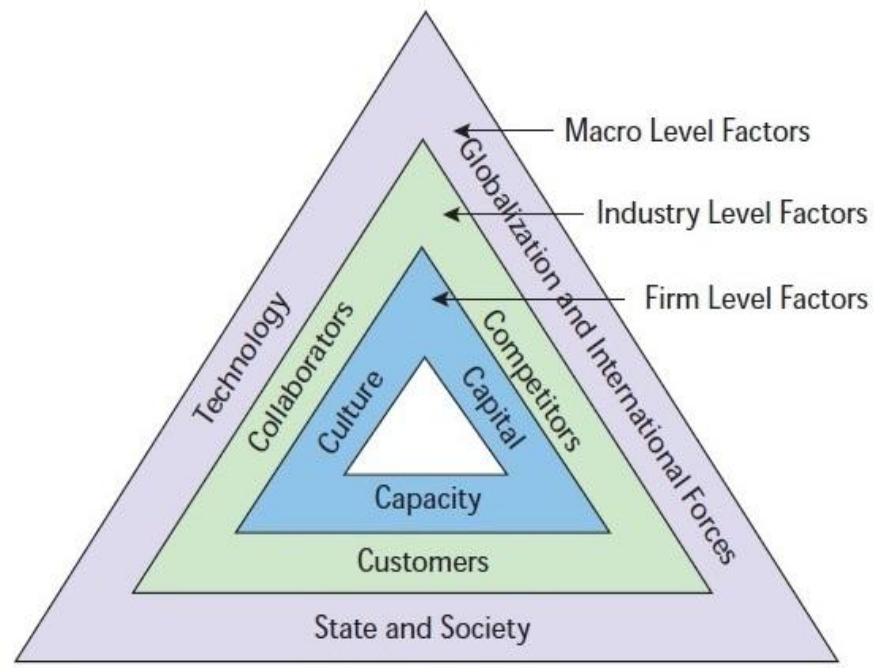

Source: Jahan (2008a).

Figure 1 Triple triangle frameworks

TTF consists of three triangles that are summarizing the factors that affect business competitiveness at different levels. The inner triangle - with each of the three sides symbolizing either capacity, or capital or culture - explains the internal, largely controllable dynamics of firms. The middle triangle - with each of its three sides symbolizing either a customer, or a competitor or a collaborator - describes the immediate, industrylevel context in which firms work. The outer triangle - with each of the three sides symbolizing either technology, or state or society and global forces - presents the macro environment, a largely non-controllable setting in which firms have to operate.

\subsection{Limitations}

Due to time and resource constraints, the study unable to provide an extensive research using qualitative research instruments. Access to certain specific information was not always possible. However, despite severe time and resource constraints, the use of multiple primary research instruments like field visits, depth interviews with key informants and focused group discussions helped gain very effective and meaningful industry assessments.

\section{An Overview Of The Boutique Industry}

In current years, swiftly embryonic technologies, brutal competition and demanding customers have contributed to a continuous increase of product variety in almost all product categories (Ho and Tang 1998). Product variety that matches customer demand let firms charge higher selling price and/or increase sales volume. Increasing product variety has somewhat positive impact over the product line's revenue. However, the exact effect is usually difficult to state, especially when customer demand is stochastic and difficult to understand (Null Lifang $\mathrm{Wu}, 2007$ ). The findings reveal that it is not just tangible things that can affect a shopper's experience, but store traits such as smell, lighting and presence of owner-manager can also influence a consumer's experience (Daniel Wade Clarke, Patsy Perry, Hayley Denson-2012). Researchers in these fields argue that higher product variety creates considerable challenges for manufacturing operations. With an increasingly complex product mix comes an additional part, less accurate demand forecasts, greater inventory and material handling, additional setups, more complex scheduling and task assignment, greater chance of 
quality problems, and increased supervisory necessities. As a result, greater resources must be committed to handle the increasing number of transactions and manufacturing contingencies and ensure the smooth operation of the plant. Although greater product variety is extensively believed to be associated with higher manufacturing expenditures, empirical studies show mixed results.Research using the Profit Impact of Marketing Strategies (PIMS) data base found that significant market share benefits accrued from broader product lines, but observed no relationship between self-reported production costs and product variety (Kekre and Srivasan, 1990). However, the Fabric worth Boutique is faced with the problem of addressing the factors that influence business atmosphere in Shanghai. This includes the legal, cultural, and geographic factors that will influence operational activities for the company (Abrahamson, and Janet, 2007).From the literature review we see that earlier researcher conducted their work on customer satisfaction, business environment, marketing strategies, and problems etc. regarding product varieties. In this paper firstly, the product varieties of boutique shops in Bangladesh is shown as well as here is given an analysis and discussion from which it will be straightforward to understand the supply side dynamics of boutique fashion is a key factor for this business expansion.

\subsection{The boutique fashion industry in Bangladesh}

There are many large and famous boutique houses in Dhaka city among them some are internationally recognized. Arong is one of them, which is a sister concern of Brac Organization. Rang, Shadakalo, Bibiana, Anjans, Nipun, K-kraft, nagordola, Deshal, M-kraft, etc are various boutique houses of Dhaka city with many braches in different areas of Dhaka city. The Bangladesh government is set to declare the flourishing boutique business as a new 'thrust sector', the commerce minister said on March, 2012, "We will declare it as a 'thrust sector' to help expansion of the industry which employs a huge number of our women labour force". The boutique industry has an estimated annual turnover of Tk 6000 crore, or 1 percent of Bangladesh's total GDP, Prof AKM Abduj Jaher of the National University said in a paper presented at a seminar in the capital. There are at least 5000 boutiques, or small fashion houses, in Bangladesh, with an estimated investment of Tk 250 crore. "The government is ready to provide funds for training in the sector and betterbank loan facilities will be provided to the entrepreneurs of this sector (Sabina,2010).

\subsection{Supply side dynamics of boutique fashion industry}

Although the boutique industry is growing slowly, it exists in a dynamic and competitive environment. In order to improve profitability, many small companies are restructuring to create leaner organizations and adopt new technologies. Consolidation has been prevalent in this industry in the past few years, as larger companies gain leverage in market position and cost cutting. In the boutique industry, companies can operate as retailers or manufacturers (wholesalers) or both. For instance, Sada Kalo, a vertical retailer, manufactures and markets their own products through retail outlets. A company like Ritu Raj is a manufacturer and sells its products to both retailers and consumers through online shop. We assume that the boutique fashion firm is involved in the production, branding and retail of fashion products. There may have many forward and backward linkage industries like color, fabrics and accessories industries etc.

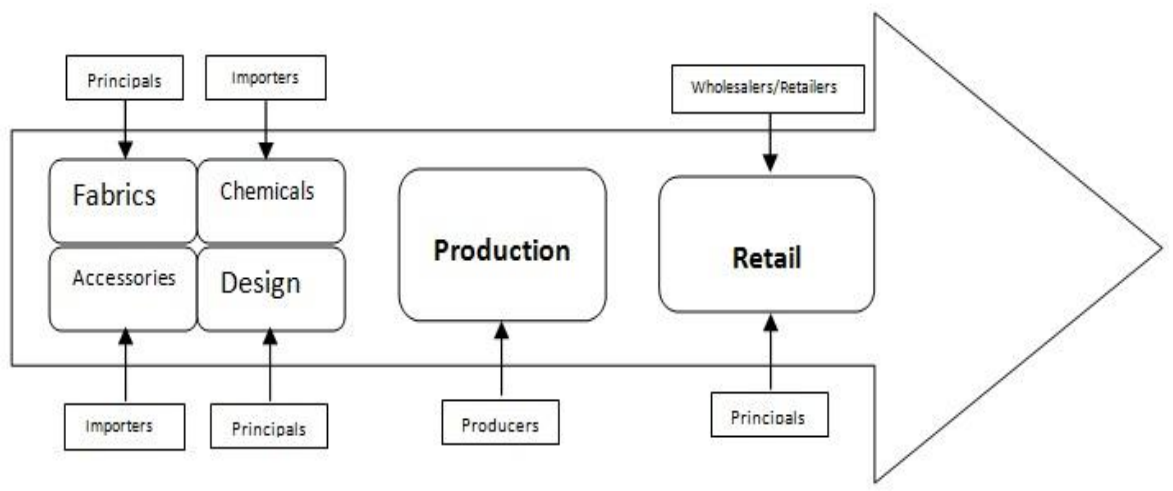

Figure 2 Value chain of boutique fashion

\subsection{Value chain governance}

The historical antecedents of the global value chain (GVC) literature lie within world systems theory. Wallerstein (1974) developed a core-periphery model, in which Northern industrialized nations are located in the central core and linked with developing Southern nations in the periphery through global commodity chains (GCCs). As the GCC literature developed, it shifted the world systems theory discourse from the macro to the micro level, through its focus on the organization of industry and firms within a more integrated global economy (Gereffi, 1999; Gereffi and Korzeniewicz, 1990). The GCC literature subsequently evolved into GVC analysis 
when researchers who studied industry clusters in specific geographic spaces sought to understand how local economic processes are conditioned by global arrangements (Gereffi and Christian, 2009).

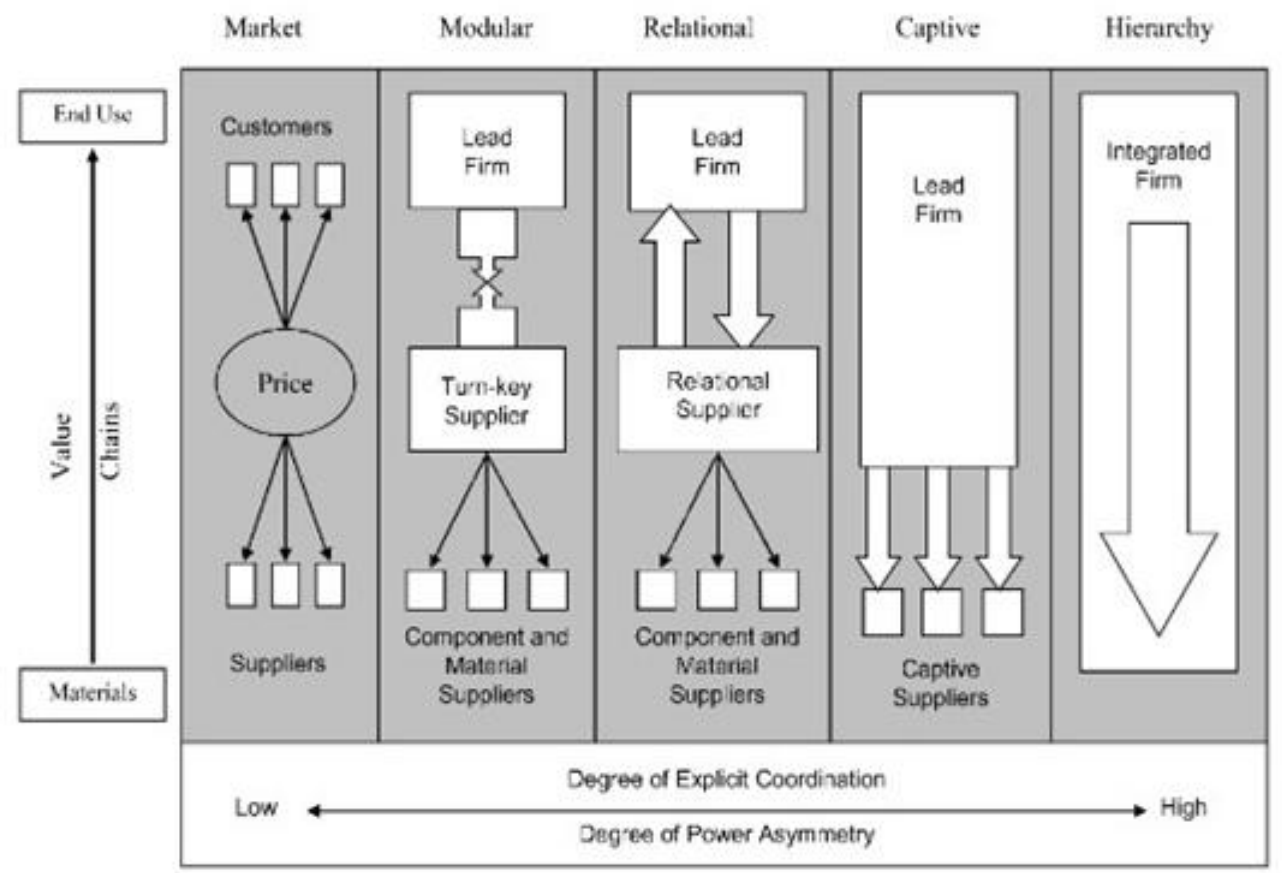

Figure 3 Five global value chain governance types

At the core of GVC analysis is the notion of governance which determines how the production and marketing of goods and services is organised globally, which in turn reflects economic power. The initial distinction made in terms of GVC governance structures was between industry-specific types - for example, whether or not structures are buyer or producer-driven (Gereffi and Korzeniewicz, 1994). The differences between these two types of governance result from who controls the dominant type of economic rent. The economic power within buyers drive GVC for lead firms - the chain drivers - results from control over the marketing and retailing nodes from which economics of scale are derived. In a producer-driven GVC, economic rents are derived from proprietary knowledge or technology, meaning that the chain drivers are located at the node of production. Within both types of GVC, however, lead firms are able to set the parameters for other participants through, for example, sub-contracting arrangements.

Because sector studies undertaken using the GVC approach subsequently highlighted a broader range of methods of coordination by chain drivers, a typology of governance structures was identified by Gereffi et al. (2005). Each type of governance is distinguished by the degree of coordination between actors at different value chain nodes and stages of production, which is a Function of: the complexity of a transaction, the ability to codify aspects of it, and the capabilities of producers. The governance structures posited range from marketbased to hierarchical structures and vary according to the depth of inter- and intra-firm relations and the degree of explicit coordination required, which is expected to increase with the complexity of the transaction (see Table 1).

Table 1. Key determinants of global value chain governance

\begin{tabular}{lcccc}
\hline Governance structure & Complexity & Codification & Capabilities & Degree of explicit coordination \\
\hline Market & Low & High & High & Low \\
Modular & High & High & High & High \\
Relational & High & Low & Low & High \\
Captive & High & High & Low & Low \\
Hierarchy & High & Low &
\end{tabular}

Source: Adapted from Gereffi et al. (2005).

A degree of control by an agency over an entire value chain, supply chain or production network is value chain governance (Jahan,2008). We have tried to understand the relation between small boutique fashion wear producer and retailer in value chain governance perspective. Governance of a value chain in the boutique fashion sector in Bangladesh varies, depending on the size of a manufacturer and the business model used. With 
small contractual production, the contract principal supplies fabrics and design to producer. The producer's role is limited to final product manufacturing as required by the principal. In this case, the value chain is fully governed by the principal who only pays for labor and production facilities and utilities costs plus the margin. The boutique fashion GVC is generally considered to exhibit the most captive governance structure of all organizations analyzed in this article, and is also buyer driven. This is where the complexity of the transaction is high, but the capabilities of suppliers are posited to be low.

\subsection{Triple Triangle Framework analysis}

\section{Strategic Analysis}

According to TTF in figure 1, a business environment may affect in three different levels. The first level deals with firm's internal factors that are also known as micro-level factors. The internal factors don't affect all firms at the same time. Some of the firms may be affected more than the others. The second tier deals with industry level factors that are also called macro level factors which affect all the firms across the industry. The third tier deals with macro-level factors which include infrastructure, state policy and even globalization framework. The questionnaire survey covered 39 major small and medium enterprise boutique businesses that that are from Mohakhali, Mohammadpur and Mirpur areas in Dhaka. This is shown in Table 3.1.

Table 2 Cluster

\begin{tabular}{|l|l|l|l|}
\hline Cluster & No & Percentage & Cumulative \\
\hline Mohakhali & 7 & $18 \%$ & $18 \%$ \\
\hline Mohammadpur & 12 & $31 \%$ & $49 \%$ \\
\hline Mirpur & 20 & $51 \%$ & $100 \%$ \\
\hline Total & 39 & $100 \%$ & \\
\hline Source: Field survey & \multicolumn{4}{|l}{} \\
\hline
\end{tabular}

Firm's internal or micro-level factors Microeconomics involves factors of resources availability and usage that impact businesses. As a company operator, understanding the core microeconomic factors affecting business helps in planning and preparation, as well as long-term business strategy development. According to TTF, three microeconomic factors that affect almost any business are capital, capacity and culture.

Survey result shows that 70 percent are registered under sole proprietorship act and 30 percent are under partnership act. This is shown in figure 3.2

Table 3 Ownership pattern

\begin{tabular}{|l|l|l|l|}
\hline Ownership & No & Percentage & Cumulative \\
\hline Soul proprietorship & 28 & 72 & 72 \\
\hline Partnership & 11 & 28 & 100 \\
\hline Private limited & 0 & 0 & 100 \\
\hline Public limited & 0 & 0 & 100 \\
\hline Total & 39 & 100 & \\
\hline Source: Field survey & \\
\hline
\end{tabular}

Table 3.3 shows that 30 percent of the firms surveyed had initial investment of below taka 5lac. Other 69 percent were with initial investment between taka 5lac to 50lac.

Table 4 Initial investment

\begin{tabular}{|l|l|l|}
\hline Investment & No & Percentage \\
\hline Below Tk 5,00,000 & 12 & 31 \\
\hline Between Tk 5,00,000 to 50,00,000 & 27 & 69 \\
\hline Between 50,00,000 to 1 crore & 0 & 0 \\
\hline Total & 39 & 100 \\
\hline Source: Field survey & \multicolumn{2}{|l|}{} \\
\hline
\end{tabular}

Table 3.4 shows that nearly 64 percent of them employ less than 25 full time employees per firm, while the next largest group consists of 28 percent of firms employed between 25 to 50 and the rest employ between 51 to 150 persons.

Table 5 Full time employees

\begin{tabular}{|l|l|l|}
\hline Number of full tim employees & No & Percentage \\
\hline Less than 25 & 25 & 64 \\
\hline 25 to 50 & 11 & 28 \\
\hline 51 to 150 & 3 & 8 \\
\hline Above 150 & 0 & 0 \\
\hline Total & 39 & 100 \\
\hline
\end{tabular}


Table 3.5 shows that the main obstacles faced by the boutique firms in getting loans due to lack of proper papers like business plan, loan proposal etc. Almost 26percent think that lack of collateral asset is obstacle for getting bank loan.

Table 6: Obstacles for bank loan

\begin{tabular}{|l|l|l|}
\hline Investment & No & Percentage \\
\hline High interest & 7 & 18 \\
\hline Too much paper work & 22 & 56 \\
\hline Collateral & 10 & 26 \\
\hline Total & 39 & 100 \\
\hline
\end{tabular}

Besides more than 80 percent entrepreneurs were found to have no training in terms of boutique business. The factors that impact boutique business growth and expansion are given below:

1. Insufficient trained and experienced cutting machine and sewing machine operator.

2. Limited access to institutional loan.

3. Workers are always unstable.

4. Lack of plans for future expansion and growth.

\section{Industry-level factors}

The complexity of the boutique fashion industry explores from manufacturing to marketing to distribution in industry level factors. Finding ways to innovate and simplify are keys to surviving in the competitive fashion industry.We found from survey that boutique producer sells nearly 51 percent in retail market, 5 percent in online shop, 15 percent sells to brand shop, and 28 percent to whole sale market. Clearly the linkage between the large industries and small boutique is the weakest of all according to our findings. Moreover, some said that they will be interested to find new markets abroad to sell their products.

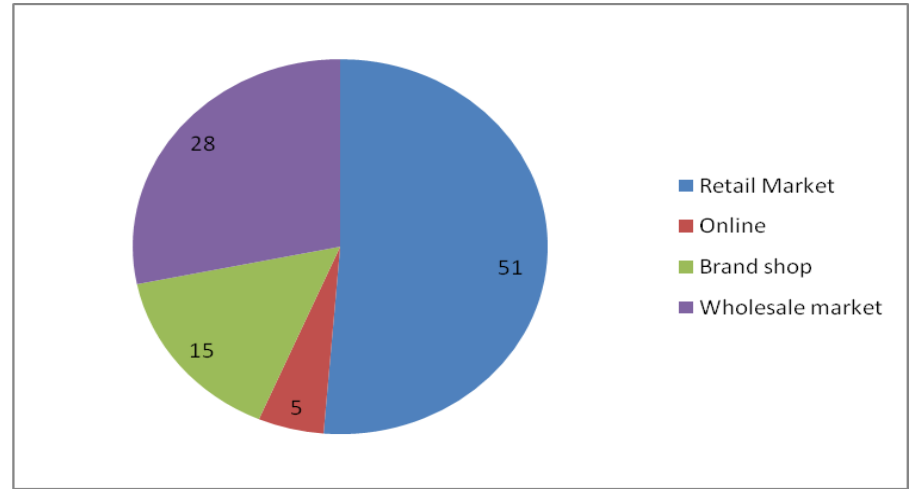

Figure 4 Market mix

\section{Consumer Factors}

Consumer factors include demographics, cultures and lifestyle. These factors affect the clothing industry in different ways. For example, a small clothing manufacturer needs to create new styles like loosefitting styles that appeal to those of different cultures, especially if those cultural groups represent large enough segments of its market. Contrarily, clothing manufacturers, wholesalers and retailers avoid creating too many that will fall outside for another new style. In that situation, ready- made garments importer make profit by absorbing the market demand.

\section{Competitors}

Consumer chooses to buy fashion wear based on personal taste, status needs and financial condition. Many fashion brands compete in price ranges to appeal to different consumer price points. A fashion house that made its mark in couture, for example, often develops a ready-to-wear line for retailers and a discount line for mass-merchandisers. They have not ability to launch in their chosen niche market might depend on controlling their design, sourcing raw materials and production costs to present their line at the appropriate price point. Hence small boutique business is growing so fast and they are facing problems for surviving in domestic market.

\section{Collaboration}

Collaboration can help address many of the boutique industry's challenges by joining areas of development that typically have trouble connecting. Conversations with over thirty boutique owners and 
professionals revealed that collaboration demands communication, and that when the right elements are in place, the result is more accuracy and better decision making.

\section{Macro-level factors}

Macro level factors affecting the boutique industry are those which lie outside small companies and their competitors. Business owners have less control of these external factors, and their impact in changing them is minimal. Instead, small companies must adapt to the macro level factors, which include technology, government influence and the policy and globalization. The way small companies adapt to macro level factors determines both their ability to differentiate themselves from key competitors and overall success. Technological Factors: Generally a small boutique house has about twenty workers for using the machines like cutting, sewing, embroidery and iron. We found maximum machines are above ten years old technology. Technological factors affecting the clothing industry include availability of resources, demand and production. For example, the scarcity of certain materials, such as cotton fabrics, may force retail and wholesale clothing companies to sell more artificial or substitute cotton products. Retailers may increase the prices of cotton clothing if they encounter shortages of this raw material, as they must pay their manufacturers more. The introduction of new clothing styles by a competitor can shift demand away from older fashions. Hence, a small clothing manufacturer may need to discontinue certain clothing lines and produce new ones that meet the needs of consumers. Moreover, clothing companies may add more advanced equipment in their plants, which may force companies to reduce overhead cost.

Legal and Political Factors: A number of legal and political macro environmental factors affect small businesses in the boutique industry. The industry has repeatedly been affected by issues such as workers' rights and child labor laws. Workers wages or other benefits are less favorable than workers in comparable industries. Workers leaving their clothing employers impacts production. This can cause delays for retailers in getting spring or fall fashions on time. This negative environment may impact also a small clothing retailer's sales and profits. Also, a trade facility to another company's imports would affect the growth of boutique industry.

\section{Conclusion}

One major question we should pose is this: what solution can be offered to the plight of small boutique enterprises in Bangladesh for inclusive growth? Firstly, policies should aim to encourage and promote the development of local technologies. Emphasis should be placed on the promotion of the local tools industry to reduce reliance on imports. Small enterprises are said to face a "liability of smallness". Because of their size and resource limitations, they are unable to develop new technologies or to make vital changes in the existing ones. Still, there is evidence that SMEs have the potential to initiate minor technological innovations to suit their circumstances. However, for small boutique enterprises to fully develop and use this potential, they need specific policy measures to ensure that technological services can be provided and requisite infrastructures are available. Further, research and development institutions that are publicly funded should be encouraged to target the technology needs of boutique industry.

Secondly, the government should come up with training centers for offering managerial and technical courses for small enterprises entrepreneurs. Equally, there should be business information centers.

Thirdly, the government should come up with proper regulatory policies that are small enterprises friendly. Since many of what we have in Bangladesh hampers every effort made by a junior entrepreneur, the policies we have seemed to care for the well-established businesses.

Fourthly, a majority of small enterprises lack finance, the government should establish a friendly small loaning system. This would include low interests rates to ensure the continuity of these businesses. Boutique industry has the potentiality of transforming the economy of a crippling nation. As such, every effort should be made to boost their growth.

\section{References}

[1]. Sen, A. (2008). The US fashion industry: A supply chain review. International Journal Production Economics , 571-593.

[2]. Moazzem, Khondaker Golam. February, 2008. Building Women in Business: A Situation Analysis of Women Entrepreneurs in Bangladesh, Bangladesh Women Chamber of Commerce and Industry (BWCCI). Strategies for Entrepreneurship Development in Bangladesh: Unleashing the Potentials of SMEs

[3]. Md. Mazedul Islam and Adnan Maroof Khan. Bangladeshi Local Apparel Products Need Proper Branding to Sustain in the Competitive Market. Department of Textile Engineering, Daffodil International University

[4]. Dr. Md. Selim Reza, Md. Abu Issa Gazi, Md. Asaf-Ud- Doula; Socio-Economic Impacts of Women Entrepreneurs in Bangladesh: Challenges and Anticipations, Banglavision, Vol. 13. No. 1. January 2014.

[5]. Akram Hossain, PhD, Sigma Islam, Shadrul Hassan Himel. Customers' Attitude Determinants and Positioning of Different Boutique Houses: A Study on Some Selected Boutique Houses in Dhaka City of Bangladesh. European Journal of Business and Management, Vol.6, No.29, 2014.

[6]. Socio-Economic Impacts of Women Entrepreneurs in Bangladesh: Challenges and Anticipations [Published by: Dr. Md. Selim Reza, Md. Abu Issa Gazi, Md. Asaf-Ud- Doula; Banglavision, Vol. 13 • No. 1 • January 2014] 
[7]. Economic Policy Paper on Benchmarking of Regional SME Policies: Identification of Policy Intervention Areas for Bangladesh [Prepared under The DCCI-CIPE, ERRA Project, (CIPE is an affiliate of the U. S. Chamber of Commerce, Washington, D.C., USA)]

[8]. Handbook on Women-owned SMEs Challenges and Opportunities in Policies and Programs, [Published by: Ingrid Andersson, Ananya Raihan, Milagros Rivera, Idris Sulaiman, Nidhi Tandon, Friederike Welter; 2007, International Organisation of Knowledge Economy and Enterprise Development (IKED)]

[9]. Karim, Nilufer Ahmed (2001), Jobs, Gender and Small Enterprises in Bangladesh: Factors Affecting Women Entrepreneurs in Small and Cottage Industries in Bangladesh, International Labour Office Geneva and ILO, Dhaka, Bangladesh.

[10]. Mazedul Islam and Adnan Maroof Khan, Bangladeshi Local Apparel Products Need Proper Branding to Sustain in the Competitive Market, Research Journal of Engineering Sciences, Vol. 2(3), 52-57, March (2013).

[11]. Nayeema Ahmed, Nadia Ahmed; Consumer Behavior towards Clothing Apparel of Designer Brands: A Study on the Boutiques and Fashion Houses in Bangladesh, Journal of Business Studies, Vol. XXXIV, No. 3, December 2013.

[12]. Professor Dr. M. A. Jalil, SME: An Instrument for Encouraging Rural Employment Generation and Contributing More to Export Earnings.

[13]. Qamruzzaman, Md.; Productivity and Performance Evaluation of SME Sector in Bangladesh: Evidence from the Historical Data, Journal of Islamic Finance and Business Research Vol. 3. No. 1. March 2015 Issue. Pp. 14 - 22.

[14]. Rahman, Md. Mominur, Product Varieties: An Analysis of Impact on Boutique Business in Bangladesh, The International Journal's Research Journal of Economics and Business Studies, Volume: 02, Number: 12, October-2013.

[15]. Rashid, Md Mamunur, Proposed Research Direction For Sustainable Smes In Bangladesh, Volume: 6, Issue: 3, Page: 317-329, January - February, 2012.

[16]. Shahnur Azad Chowdhury, Md Kazi Golam Azam, \& Serajul Islam; Problems and Prospects of SME Financing in Bangladesh, Asian Business Review, Volume 2, Numebr 2/2013 (Issue 4).

[17]. Syed Saifuddin Hossain, Uttam Deb, Muhammad Al Amin; Impact Of Information Technology In Trade Facilitation On Small And Medium-Sized Enterprises In Bangladesh, Occasional Paper: 84, Centre for Policy Dialogue (CPD). 